Xiao-Ling Li*, Ling-Yun Xin, Yue-Yi Yu, Qing-Qing Yang and Meng-Ke Liu

\title{
Crystal structure of bis[triaqua- $\left(\mu_{2}-1,2-\mathrm{di}(4-\right.$ pyridyl)ethylene- $\left.\mathrm{K}^{2} N: N^{\prime}\right)$-(4-sulfonatobenzoato- $\left.\mathrm{K}^{2} \mathrm{O}, \mathrm{O}^{\prime}\right)$ zinc(II)], $\mathrm{C}_{13} \mathrm{H}_{15} \mathrm{NO}_{8} \mathrm{SZn}$
}

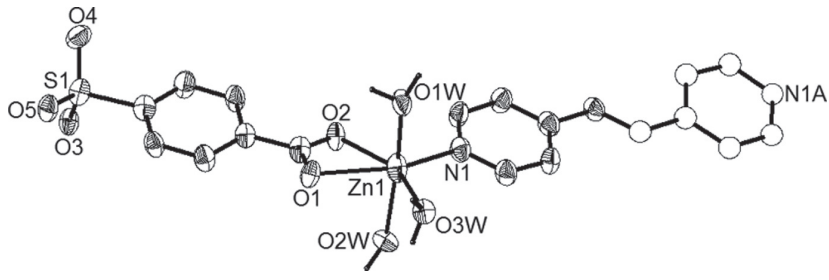

https://doi.org/10.1515/ncrs-2019-0558

Received August 3, 2019; accepted September 22, 2019; available online October 11, 2019

\begin{abstract}
$\mathrm{C}_{13} \mathrm{H}_{15} \mathrm{NO}_{8} \mathrm{SZn}$, monoclinic, $C 2 / c$ (no. 15), $a=12.3456(3) \AA$, $b=13.7680(4) \AA, \quad c=19.9125(5) \AA, \quad \beta=107.051(2)^{\circ}$, $V=3235.85(14) \AA^{3}, Z=8, R_{\mathrm{gt}}(F)=0.0325, w R_{\text {ref }}\left(F^{2}\right)=0.0819$, $T=293(2) \mathrm{K}$.
\end{abstract}

CCDC no.: 1955111

The asymmetric unit of the dinuclear title structure is shown using ellipsoids in the figure. Table 1 contains crystallographic data and Table 2 contains the list of the atoms including atomic coordinates and displacement parameters.

\section{Source of material}

All chemicals were used as obtained without further purification. The mixtures of potassium 4-carboxybenzenesulfonate (4-khsb) (0.1 mmol, $24.03 \mathrm{mg}), \quad$ 1,2-di(4-pyridyl)ethylene (bpe) $(0.05 \mathrm{mmol}, 9.18 \mathrm{mg}), \mathrm{Zn}(\mathrm{Ac})_{2} \cdot 2 \mathrm{H}_{2} \mathrm{O} \quad(0.1 \mathrm{mmol}$, $21.9 \mathrm{mg}$ ), ethanol $(3.0 \mathrm{~mL})$, and $\mathrm{H}_{2} \mathrm{O}(3.0 \mathrm{~mL})$ were sealed in a $23 \mathrm{~mL}$ Teflon-lined autoclave, heated to $393 \mathrm{~K}$ for 4 days, then cooled at $5{ }^{\circ} \mathrm{C} \mathrm{h}^{-1}$ to room temperature. Colorless block crystals were obtained.

\footnotetext{
*Corresponding author: Xiao-Ling Li, College of Chemistry and Chemical Engineering, LuoYang Normal University, Luoyang, Henan 471934, PR China, e-mail: lixiaoling030812@163.com. https://orcid.org/0000-0001-6654-6143

Ling-Yun Xin, Yue-Yi Yu, Qing-Qing Yang and Meng-Ke Liu: College of Chemistry and Chemical Engineering, LuoYang Normal University, Luoyang, Henan 471934, PR China
}

๑ Open Access. () 2019 Xiao-Ling Li et al., published by De Gruyter. (๕) BY License.
Table 1: Data collection and handling.

\begin{tabular}{ll}
\hline Crystal: & Colourless block \\
Size: & $0.38 \times 0.34 \times 0.31 \mathrm{~mm}$ \\
Wavelength: & Mo $K \alpha$ radiation $(0.71073 \AA)$ \\
$\mu:$ & $1.69 \mathrm{~mm}^{-1}$ \\
Diffractometer, scan mode: & SuperNova, $\omega$ \\
$\theta_{\text {max }}$, completeness: & $28.4^{\circ},>99 \%$ \\
$N(h k l)_{\text {measured }}, N(h k l)_{\text {unique }}, R_{\text {int }}:$ & $11762,3481,0.027$ \\
Criterion for $I_{\text {obs }}, N(h k l)_{\text {gt }}:$ & $I_{\text {obs }}>2 \sigma\left(I_{\text {obs }}\right), 3031$ \\
$N(\text { param })_{\text {refined }}:$ & 217 \\
Programs: & CrysAlis \\
& Olex2 [3] $[1]$, SHELX [2], \\
\hline
\end{tabular}

\section{Experimental details}

The structure was solved and refined using the SHELX and OLEX2-system [1, 2]. Hydrogen atoms bonded to the carbon atoms were placed in calculated positions and refined with a riding mode. The water hydrogen atoms were initially located in the difference Fourier maps.

\section{Comment}

The design and construction of diverse metal complexes has attracted great attention in recent years because of the enormous variety of intriguing structure as well as their potential applications in many fields [4-6]. To the best of our knowledge, 4-khsb is a good candidate for the construction of complexes that display rich structural diversity, due to their extension ability both in covalent bonding and in supramolecular interactions (H-bonding and aromatic stacking) [7-10]. Furthermore, N-donor ancillary ligand can modify the structures and properties of the resulting materials. So far very interesting and promising results are constructed by mixed likers. With these considerations in mind, we report herein a dinuclear $\mathrm{Zn}$ (II) complex.

The asymmetric unit of the title complex contains one crystallographically independent $\mathrm{Zn}$ (II) center, one 4-sb ${ }^{2-}$ anion, a half bpe ligand and three coordination water molecules (see the figure). The $\mathrm{Zn} 1$ atom resides in a distorted octahedral environment $\left[\mathrm{ZnO}_{5} \mathrm{~N}\right]$ with the basal plane defined by $\mathrm{O} 1$ and $\mathrm{O} 2$ atoms from the carboxyl group of one 4-sb ${ }^{2-}$ anion and $\mathrm{O} 3 \mathrm{~W}$ from one coordination water molecule as well as N3 from one bpe molecule. Two $\mathrm{O}$ atoms (O1W and O2W) 
Table 2: Fractional atomic coordinates and isotropic or equivalent isotropic displacement parameters $\left(\AA^{2}\right)$.

\begin{tabular}{|c|c|c|c|c|}
\hline Atom & $x$ & $y$ & $z$ & $\boldsymbol{U}_{\text {iso }} * / \boldsymbol{U}_{\mathrm{eq}}$ \\
\hline $\mathrm{Zn} 1$ & $0.54265(2)$ & $0.67311(2)$ & $0.45790(2)$ & $0.02716(10)$ \\
\hline S1 & $0.83898(5)$ & $0.50448(5)$ & $0.88844(3)$ & $0.02908(14)$ \\
\hline 01 & $0.71180(15)$ & $0.65672(13)$ & $0.55134(9)$ & $0.0383(4)$ \\
\hline $01 \mathrm{~W}$ & $0.53705(16)$ & $0.81464(13)$ & $0.49183(10)$ & $0.0445(5)$ \\
\hline H1WA & 0.5736 & 0.8185 & 0.5352 & $0.067^{\star}$ \\
\hline H1WB & 0.4980 & 0.8661 & 0.4890 & $0.067^{*}$ \\
\hline 02 & $0.54207(14)$ & $0.62057(13)$ & $0.55678(8)$ & $0.0369(4)$ \\
\hline $02 \mathrm{~W}$ & $0.57738(15)$ & $0.53409(13)$ & $0.42577(10)$ & $0.0411(4)$ \\
\hline $\mathrm{H} 2 \mathrm{WA}$ & 0.6296 & 0.4926 & 0.4290 & $0.062^{*}$ \\
\hline $\mathrm{H} 2 \mathrm{WB}$ & 0.5251 & 0.4949 & 0.4276 & $0.062^{*}$ \\
\hline 03 & $0.81569(15)$ & $0.40008(13)$ & $0.88624(9)$ & $0.0394(4)$ \\
\hline O3W & $0.62555(14)$ & $0.71734(13)$ & $0.38827(8)$ & $0.0345(4)$ \\
\hline H3WA & 0.6633 & 0.6688 & 0.3811 & $0.052^{*}$ \\
\hline H3WB & 0.6717 & 0.7630 & 0.4056 & $0.052^{*}$ \\
\hline 04 & $0.77728(16)$ & $0.55695(15)$ & $0.92854(9)$ & $0.0438(5)$ \\
\hline 05 & $0.95914(14)$ & $0.52554(14)$ & $0.90855(9)$ & $0.0393(4)$ \\
\hline N1 & $0.37271(16)$ & $0.67166(14)$ & $0.40144(10)$ & $0.0287(4)$ \\
\hline $\mathrm{C} 1$ & $0.6484(2)$ & $0.62631(17)$ & $0.58547(12)$ & $0.0303(5)$ \\
\hline $\mathrm{C} 2$ & $0.69611(19)$ & $0.59643(17)$ & $0.66059(11)$ & $0.0272(5)$ \\
\hline $\mathrm{C} 3$ & $0.6251(2)$ & $0.5854(2)$ & $0.70241(13)$ & $.0383(6)$ \\
\hline H3 & 0.5477 & 0.5960 & 0.6836 & $0.046^{*}$ \\
\hline $\mathrm{C} 4$ & $0.6686(2)$ & $0.5585(2)$ & $0.77216(12)$ & $0.0390(6)$ \\
\hline $\mathrm{H} 4$ & 0.6207 & 0.5508 & 0.8002 & $0.047^{*}$ \\
\hline C5 & $0.78323(18)$ & $0.54346(17)$ & $0.79971(11)$ & $0.0258(5)$ \\
\hline $\mathrm{C} 6$ & $0.8548(2)$ & $0.55506(19)$ & $0.75893(12)$ & $0.0340(6)$ \\
\hline H6 & 0.9323 & 0.5455 & 0.7782 & $0.041^{*}$ \\
\hline $\mathrm{C} 7$ & $0.8113(2)$ & $0.58107(19)$ & $0.68903(12)$ & $0.0347(6)$ \\
\hline $\mathrm{H} 7$ & 0.8595 & 0.5882 & 0.6612 & $0.042^{*}$ \\
\hline $\mathrm{C} 8$ & $0.2911(2)$ & $0.6638(2)$ & $0.43257(13)$ & $0.0382(6)$ \\
\hline $\mathrm{H} 8$ & 0.3120 & 0.6570 & 0.4811 & $0.046^{*}$ \\
\hline $\mathrm{C} 9$ & $0.1773(2)$ & $0.6653(2)$ & $0.39625(13)$ & $0.0402(6)$ \\
\hline H9 & 0.1234 & 0.6594 & 0.4203 & $0.048^{*}$ \\
\hline $\mathrm{C} 10$ & $0.14351(19)$ & $0.67578(17)$ & $0.32361(12)$ & $0.0310(5)$ \\
\hline C11 & $0.2290(2)$ & $0.68347(19)$ & $0.29133(13)$ & $0.0348(6)$ \\
\hline $\mathrm{H} 11$ & 0.2107 & 0.6901 & 0.2428 & $0.042^{*}$ \\
\hline C12 & $0.3403(2)$ & $0.68119(19)$ & $0.33127(13)$ & $0.0347(6)$ \\
\hline $\mathrm{H} 12$ & 0.3961 & 0.6865 & 0.3086 & $0.042^{*}$ \\
\hline C13 & $0.0216(2)$ & $0.67632(18)$ & $0.28455(13)$ & $0.0349(6)$ \\
\hline $\mathrm{H} 13$ & -0.0293 & 0.6767 & 0.3109 & $0.042^{*}$ \\
\hline
\end{tabular}

from two coordination water molecules are positioned at the axial positions. All the $\mathrm{Zn}-\mathrm{O}$ bond lengths are in the range of 2.0429(16)-2.3653(17) $\AA$ and the $\mathrm{Zn}-\mathrm{N}$ bond is 2.0695(19) $\AA$. The sulfonate group remains uncoordinated. The adjacent $\mathrm{Zn} \cdots \mathrm{Zn}$ atoms are separated by one bpe connector $13.528 \AA$.

There are hydrogen bonds between coordinated water oxygen atoms and coordinated oxygen atoms of carboxylate $\left(\mathrm{O} 2 \mathrm{~W}-\mathrm{H} 2 \mathrm{WB} \cdots \mathrm{O}^{4}\right.$ with the donor-acceptor distance of 2.670(2) $\AA$ and a bond angle of $158.6^{\circ}$ as well as 03WH3WB $\cdots 01^{5}$ with the donor-acceptor distance of 2.659(2) $\AA$ and a bond angle of $169.8^{\circ}$ ). Several kinds of hydrogen bonding between coordinated water oxygen atoms and uncoordinated oxygen atoms of the sulfonate group are observed [(1) O1W-H1WA $\cdots 03^{1}$ with the donor-acceptor distance of $2.828(2) \AA$ A and a bond angle of $146.5^{\circ}$; (2) O1W-H1WB $\cdots 05^{2}$ with the donor-acceptor distance of 2.753(3) $\AA$ and a bond angle of $129.0^{\circ}$; (3) $\mathrm{O} 2 \mathrm{~W}-\mathrm{H} 2 \mathrm{WA} \cdots \mathrm{O}^{3}$ with the donoracceptor distance of 2.754(3) $\AA$ and bond angle of $157.7^{\circ}$; (4) O3W-H3WA $\cdots 03^{3}$ with the bond distance of $2.860(2) \AA$ and a bond angle of $151.8^{\circ}$. (symmetric code: ${ }^{1} 3 / 2-x, 1 / 2+y$, $3 / 2-z ;{ }^{2}-1 / 2+x, 3 / 2-y,-1 / 2-z ;{ }^{3}+x, 1-y,-1 / 2+z$; $\left.{ }^{4} 1-x, 1-y, 1-z ;{ }^{5} 3 / 2-x, 3 / 2-y, 1-z\right)$ The weaker face to face $\pi-\pi$ stacking interactions occur between bpe (the ring of $\mathrm{N} 1 / \mathrm{C} 8-\mathrm{C} 12)$ and $4-\mathrm{sb}^{2-}$ (the ring of $\mathrm{C} 2-\mathrm{C} 7$ ) with a centroidcentroid distance is 3.8344(1) $\AA$.

\section{References}

1. Agilent, Crysalis ${ }^{\text {PRO }}$ software system, Oxford, UK (2015).

2. Sheldrick, G. M.: SHELXT-integrated space-group and crystalstructure determination. Acta Crystallogr. A71 (2015) 3-8.

3. Dolomanov, O. V.; Bourhis, L. J.; Gildea, R. J.; Howard, J. A. K.; Puschmann, H.: OLEX2: a complete structure solution, refinement and analysis program. J. Appl. Crystallogr. 42 (2009) 339-341.

4. Li, G. L.; Liu, G. Z.; Ma, L. F.; Xin, L. Y.; Li, X. L.; Wang, L. Y.: Crystallographic determination of solid-state structural transformations in a dynamic metal-organic framework. Chem. Commun. 50 (2014) 2615-2617.

5. Xin, L. Y.; Li, Y. P.; Ju, F. Y.; Li, X. L.; Liu, G. Z.: A supramolecular microporous network of zinc(II) coordination polymer for highly selective fluorescent detection of $\mathrm{Pb}^{2+}$. Indian J. Chem. 56A (2017) 826-831.

6. Ju, F. Y.; Li, Y. P.; Li, G. L.; Liu, G. Z.; Xin, L. Y.; Li, X. L.: Zinc(II) and cadmium(II) coordination polymers with various polynuclears spaced by semirigid 4-carboxybenzeneacetate and nitrogen-rich co-ligangds: synthese, structures and properties. Chin. J. Inorg. Chem. 32 (2016) 1876-1884.

7. Garcia, H. C.; Diniz, R.; de Oliveira, L. F. C.: Supramolecular architectures of metal complexes containing 4-sulfobenzoate dianion and 1,2-bis(4-pyridyl)ethane. Polyhedron 53 (2013) 40-47.

8. Wang, H.; Huo, L. H.; Deng, Z. P.; Zhao, H.; Gao, S.: Syntheses, crystal structures and luminescent properties of $\mathrm{Zn}(\mathrm{II}) / \mathrm{Cd}(\mathrm{II})$ supramolecular complexes incorporating 4-sulfifinobenzoate and its in situoxidized ligand. CrystEngComm 14 (2012) 3501-3508.

9. Wagner, C.; Merzweiler, K.: Synthesis, crystal structures and thermal properties of 4-carboxylbenzenesulfonates of iron, cobalt and zinc. Z. Anorg. Allg. Chem. 636 (2010) 557-561.

10. Zhang, J.; Zhu, L. G.: Syntheses, structures, and supramolecular assembles of zinc 4-sulfobenzoate complexes with chelating and/or bridging ligands. J. Mol. Struct. 931 (2009) 87-93. 